Revista Verde de Agroecologia e Desenvolvimento Sustentável

http://www.gvaa.com.br/revista/index.php/RVADS

ARTIGO CIENTÍFICO

DOI: http://dx.doi.org/10.18378/rvads.v10i5.4068

\title{
Interferência de tiririca (Cyperus rotundus L.) e da compactação do solo no crescimento do feijão-caupi
}

\section{Interference of nut grass (Cyperus rotundus L.) and soil compaction on cowpea growth}

Uriel Calisto Moura Pessôa ${ }^{1}$, Edvaldo Nunes da Silva Terceiro ${ }^{2}$, Anielson dos Santos Souza ${ }^{3}$, Alberto de Andrade Soares Filho $^{4}$, Thiago Alves Pimenta ${ }^{5}$

\begin{abstract}
RESUMO - As plantas daninhas interferem no crescimento e desenvolvimento da cultura do feijão-caupi, podendo reduzir drasticamente a sua produtividade. Objetivou-se com o trabalho, avaliar a interferência de Cyperus rotundus e da compactação do solo no crescimento do feijão-caupi [Vigna unguiculata (L.) Walp] no sertão paraibano. O experimento foi realizado em estufa agrícola no Centro de Ciências e Tecnologia Agroalimentar da Universidade Federal de Campina Grande, CCTA/UFCG, Campus de Pombal-PB. As unidades experimentais foram compostas por vasos com capacidade de 6 litros. Utilizou-se o delineamento inteiramente casualizado com tratamentos distribuídos em esquema fatorial 3 x 2 , sendo os fatores três populações de $C$. rotundus ( 0,2 e 3 tubérculos por vaso) e dois níveis de compactação (solo sem compactação e solo com subsuperfície compactada), com quatro repetições. Foram coletados os dados de produção de fitomassa, área foliar, altura da planta, número de folhas e diâmetro do caule, os quais foram submetidos à análise da variância e teste de médias. A presença de $C$. rotundus, independente de sua população prejudicou os componentes de crescimento, reduzindo a área foliar, de forma mais intensa do que a compactação do solo. Com isto, urgem medidas que reduzam os prejuízos causados por $C$. rotundus a cultura do feijão-caupi.
\end{abstract}

Palavras-chave: Vigna unguiculata (L.) Walp, competição, crescimento

\begin{abstract}
Weeds interfere with the growth and development of the cowpea crop and can dramatically reduce their productivity. The objective of this study was to evaluate the interference of nut grass and soil compaction in the growth of cowpea [Vigna unguiculata (L.) Walp]. The experiment was conducted in an agricultural greenhouse in the Science and Technology Center of Agrifood Federal University of Campina Grande, CCTA/UFCG, Campus de Pombal-PB, Brazil. The experimental were composed of pots with 6 liters capacity. Used a completely randomized design with treatments distributed in a factorial $3 \times 2 \times 4$, comprising the three populations of $C$. rotundus (0, 2 and 3 tubers per pot) and two compression levels (soil without compaction and soil compacted subsurface), with four replications. Were collected biomass production data, leaf area, plant height, leaf number and stem diameter, which were submitted to analysis of variance and mean test when necessary. The presence of $C$. rotundus, regardless of its population hampered growth components, reduced leaf area, more intensely than soil compaction. With this, urge measures to reduce the harm caused by $C$. rotundus the cowpea.
\end{abstract}

Keywords: Vigna unguiculata (L.) Walp, competition, growth

\footnotetext{
*Autor para correspondência

Recebido para publicação em 15/11/2015; aprovado em 23/12/2015

${ }^{1}$ Graduando em Agronomia - UFCG/CCTA - Universidade Federal de Campina Grande, Pombal-PB. E-mail: uriel.pessoa2@ gmail.com

${ }^{2}$ Bacharel em Agronomia - UFCG/CCTA - Universidade Federal de Campina Grande, Pombal-PB. E-mail: edvaldoterceiro@ hotmail.com

${ }^{3}$ Eng. Agr. D. Sc., Professor da Unidade Acadêmica de Ciências Agrárias - UFCG/CCTA - Universidade Federal de Campina Grande, Pombal-PB. E-mail: anielson@ccta.ufcg.edu.br

${ }^{4}$ Graduando em Agronomia - UFCG/CCTA - Universidade Federal de Campina Grande, Pombal-PB. E-mail: Alberto.asf10@bol.com.br

${ }^{5}$ Graduando em Agronomia - UFCG/CCTA - Universidade Federal de Campina Grande, Pombal-PB. E-mail: tpimenta62@ gmail.com
} 


\section{INTRODUÇÃO}

O feijão-caupi [Vigna unguiculata (L.) Walp] é cultivado em regiões tropicais e subtropicais, tendo ampla distribuição mundial, por ser uma das leguminosas mais adaptadas, versáteis e nutritivas, fato este, que a torna, importante espécie cultivada na região semiárida (SINGH et al., 2002).

O Nordeste brasileiro apresenta grande diversidade de lavouras cultivadas anualmente pelos pequenos e médios agricultores, tendo destaque o feijão-caupi, por sua preferência de consumo, sobretudo nas áreas mais quentes e de menor altitude. Apesar da importância socioeconômica, tal cultura ainda é, em sua maioria, cultivada de forma precária e sem uso de tecnologias apropriadas que promovam um melhor rendimento por meio de um manejo mais adequado.

As plantas daninhas constituem um dos fatores que mais influenciam o crescimento, o desenvolvimento e a produtividade da cultura do feijão-caupi, pois competem por luz, nutrientes e água, o que reflete na redução quantitativa e qualitativa da produção, além de aumentar os custos operacionais de colheita, secagem e beneficiamento dos grãos (FREITAS et al., 2009 ). Quando não controladas, as plantas daninhas podem reduzir o rendimento de grãos em até $90 \%$, devido à competição exercida pelas espécies infestantes, além de promover o aumento da altura e acamamento de plantas (MORAES et al., 2009). A intensidade da interferência da comunidade infestante sobre a cultura comercial, normalmente, é medida pelos efeitos negativos sobre a produtividade, que estão relacionados a fatores ligados à cultura, à comunidade infestante e ao ambiente.

Oliveira et al., (2011) constaram que, devido ao alto grau de infestação de plantas daninhas na cultura do feijãocaupi, houve drástica redução no estande final de três cultivares, e que no tratamento com zero dia de convivência das plantas daninhas com as de feijão-caupi, o estande final dos três cultivares não sofreu alteração em relação ao inicial. Com tais resultados, os autores concluíram que as plantas daninhas podem ter diminuído a incidência de luz sobre as plantas cultivadas, sendo esta uma das causas da redução do estande final, bem como, no número de vagens por planta e no peso de mil grãos, resultando numa baixa produtividade. $\mathrm{O}$ período anterior à interferência foi de cinco dias após a semeadura, portanto, o controle das plantas daninhas deve ser realizado no final desse período, quando se inicia o período crítico de prevenção à interferência dessas plantas (PCPI), para a cultura expressar o seu potencial produtivo.

As plantas de $C$. rotundus provocam reduções quantitativas e qualitativas na produção mundial das principais culturas. É tida como uma das espécies botânicas de maior amplitude geográfica, devido sua ampla distribuição, capacidade de competição e agressividade, além de estar presente em todos os países de clima tropical ou subtropical, e até mesmo em regiões de clima temperado (CUDNEY, 1997). Atualmente tem oferecido grande resistência aos métodos convencionais de controle (químico e mecânico), pois apresenta uma estratégia de reprodução bastante eficiente, atingindo, em condições ambientais propícias, uma multiplicação intensa e rápida.

Muitas culturas são afetadas pela presença de Cyperus rotundus L., como o milho, o feijão, o algodão e a cana-de- açúcar. Com enorme capacidade de multiplicação pode produzir até 40 tonelad

as de matéria vegetal por hectare. Para isso, extrai o equivalente a $815 \mathrm{~kg}$ de sulfato de amônio, $320 \mathrm{~kg}$ de cloreto de potássio e $200 \mathrm{~kg}$ de superfosfato simples por hectare, calculados para 30 toneladas de fitomassa (PASTRE, 2006). Além disso, sendo a tiririca, uma das mais agressivas plantas daninhas do mundo com diferentes mecanismos de propagação e disseminação e grande capacidade adaptativa a diferentes ambientes, é possível que tal espécie consiga se sobressair frente ao feijão-caupi. Todavia, tem-se verificado que, em solos compactados devido ao preparo inadequado ocorre maior incidência de plantas daninhas, com cerca de 10 $\%$ a mais de sementes germinadas no local de passagem das rodas do trator, o que reflete a capacidade de tais espécies sobreviverem em condições onde culturas agrícolas não poderiam produzir satisfatoriamente Silva e Silva (2007).

De acordo com Guimarães e Moreira, (2002), o feijoeiro é, entre outras culturas, muito sensível à compactação do solo. A compactação, ao limitar o crescimento radicular das plantas compromete sua capacidade em absorver nutrientes e água e a própria fixação ao solo, causando debilitação e acamamento, sobretudo quando a camada de compactação é superficial. A compactação afeta a parte aérea das plantas, reduzindo a área foliar e a produtividade.

Num entanto, Castellane et al., (2006), ao estudar a interferência da compactação no desenvolvimento e produção da soja, observou efeito linear sobre algumas características de crescimento da cultura, que segundo o autor, não resultou em decréscimo significativo da produção.

Diante do exposto, objetivou-se, avaliar a interferência de $C$. rotundus L. e da compactação do solo no crescimento e na produção de fitomassa da cultura do feijão caupi, no sertão paraibano.

\section{MATERial e Métodos}

O trabalho foi realizado em uma estufa agrícola no Centro de Ciências e Tecnologia Agroalimentar da Universidade Federal de Campina Grande no Campus de Pombal, onde foi utilizado o delineamento experimental inteiramente ao acaso (DIC), com tratamentos arranjados em esquema fatorial $3 \times 2$, sendo os fatores três populações de $C$. rotundus ( 0,2 e 3 tubérculos por vaso) e dois níveis de compactação (solo sem compactação e solo com subsuperfície compactada), totalizando 24 unidades experimentais, cada uma composta por um vaso com capacidade de seis litros, semanalmente, os vasos tinham a posição alterada, visando reduzir efeitos de local.

Para a montagem do experimento foram coletados em área agrícola infestada com Cyperus rotundus, na zona rural do município de Pombal-PB, cem tubérculos de tal espécie, os quais foram levados ao laboratório de Fitotecnia da UAGRA/CCTA, lavados em água corrente e plantados em bandeja plástica utilizando-se como substrato areia lavada, com o intuito de se verificar a viabilidade dos tubérculos antes do plantio definitivo.

Para enchimento dos vasos utilizou-se substrato composto por $90 \%$ de solo peneirado e seco ao ar com textura média e $10 \%$ de esterco de curral curtido, a essa mistura foi adicionado o equivalente a $10 \%$ da massa do substrato de água por ocasião da homogeneização do substrato. A massa unitária de cada vaso era de 170 gramas e 
após enchidos apresentam massa média de 5.830 gramas, de acordo com teste realizado previamente.

A semeadura do feijão-caupi e o plantio da tiririca ocorreram concomitantemente em cada unidade experimental. Foram postas por vaso quatro sementes de feijão-caupi, sendo realizado o desbaste, 15 dias após a emergência das plântulas, cortando- as rente ao solo de modo que permanecessem duas plantas por vaso. Já os tubérculos de $C$. rotundus, selecionados previamente, foram distribuídos ao número de dois ou três por vaso de acordo com o tratamento.

Foram feitas regas diárias, com o equivalente a $8 \%$ da massa do substrato, o que correspondeu aproximadamente a $452 \mathrm{~mL}$ de água. No decorrer do experimento verificou-se um baixo crescimento das plantas de feijão, sobretudo nos tratamentos infestados com tiririca, e como havia uma limitação de recursos disponíveis devido ao pequeno tamanho do vaso, realizaram-se aplicações periódicas com o uso de solução nutritiva para garantir melhor crescimento das plantas, tal solução foi preparada no Laboratório de Fisiologia Vegetal da UAGRA/CCTA/UFCG.

O cultivar de feijão utilizado foi o BR 17 Gurguéia desenvolvido pela Embrapa Meio-Norte em Teresina - PI, e possui as seguintes características: hábito de crescimento indeterminado com porte enramador, folha globosa, período médio de floração de 43 a 52 dias após o plantio, ciclo de 75 dias em média, flor com coloração roxa destacada pelo estandarte e pela quilha, quando imatura a vagem possui coloração verde e quando seca amarela, com comprimento médio de $17 \mathrm{~cm}$ e 15 sementes por vagem, o peso médio de 100 sementes é de $12,5 \mathrm{~g}$, as quais possuem coloração esverdeada (FREIRE FILHO, 2008).

Nos tratamentos com o solo da sub superfície compactado, a camada correspondente foi obtida mediante a compactação mecânica com o uso de um cilindro de PVC com diâmetro semelhante ao diâmetro do vaso, a saber: 150 $\mathrm{mm}$ e altura compactada de $30 \mathrm{~mm}$. A massa compactada correspondeu a $20 \%$ da massa total de substrato, que foi de 1.132 gramas.

O volume de substrato compactado foi de $495,40 \mathrm{~cm}^{3}$, e a densidade da camada compactada foi de $2,28 \mathrm{~g} \mathrm{~cm}^{3}$, considerando-se a densidade como sendo a relação entre a massa de solo e o volume do cilindro. A camada de substrato compactado foi colocada a $7 \mathrm{~cm}$ de altura em relação ao fundo do vaso e a $10 \mathrm{~cm}$ de profundidade em relação a superfície do vaso.

Além das regas como tratos culturais, ainda realizou-se, durante a condução do experimento, aplicações de defensivos agrícolas devido à ocorrência de cochonilhas e pulgões quando o feijão estava no estádio V3, sendo utilizado para o controle inseticida a base de deltamethrin 25 EC. Também foi necessária a aplicação de fungicida a base de clorotalonil (isoftalonitrila) oxicloreto de cobre (inorgânico) formulado como pó molhável, para o controle de fitopatógenos causadores de tombamento no feijoeiro.

Por duas vezes foi necessário o fornecimento de ferro a cultura, na forma de ferro EDTA, sendo $6 \mathrm{ml}$ por vaso, pois apesar da solução nutritiva utilizada para regar as plantas possuir tal nutriente, a presença de sintomas de deficiências foi comum em todos os tratamentos. Após a aplicação, a clorose internerval desaparecia em poucos dias.

Aos 81 dias após a semeadura quando as plantas estavam iniciando a floração, as unidades experimentais foram levadas ao Laboratório de Fitotecnia da UAGRA/CCTA/UFCG, para a coleta final dos dados relativos às seguintes características: 1) altura da planta; 2) número de folhas; 3) diâmetro do caule; 4) produção de fitomassa verde e seca da parte aérea e da raiz e relação raiz/ parte aérea do feijão-caupi; e 5) comprimento e diâmetro da raiz principal do feijoeiro;

A altura de plantas foi mensurada no início da floração utilizando-se uma trena graduada em centímetros, considerouse como altura, a distância vertical dada em centímetros entre o colo da planta e o ápice do ramo principal. O número de folhas foi determinado pela contagem dos trifólios, e o diâmetro do caule, foi medido na altura do segundo nó, em milímetros, com um paquímetro digital.

Para determinação da produção de fitomassa, as plantas de feijão de cada vaso, foram separadas em folhas, caules e raízes, sendo estas últimas submetidas à lavagem em água corrente até a completa eliminação do substrato. Após a separação e limpeza cada parte da planta foi acondicionada em saco de papel devidamente identificada e pesada em balança com precisão de 0,5 gramas, para obtenção da fitomassa fresca. Em seguida o material de cada repetição foi levado à estufa de circulação de ar a $65^{\circ} \mathrm{C}$ até atingir peso constante, o que foi verificado realizando-se pesagens diárias das amostras. Desse modo, obteve-se a produção de fitomassa das raízes e da parte aérea do feijoeiro.

Com a separação das plantas de feijão em raízes, caules e folhas, foi possível determinar a distribuição relativa de fitomassa seca a partir da equação 01. A relação raiz parte aérea do feijão-caupi, foi obtida dividindo-se produção de fitomassa radicular pela produção de fitomassa da parte aérea.

$$
\mathrm{PF}_{\text {(raiz, caule ou folha) }} \mathrm{x} \text { 100/PTF }
$$

Onde:

$\mathrm{PF}=$ Produção de fitomassa da raiz, do caule ou da folha $(\mathrm{g}), \mathrm{e}$

$$
\mathrm{PTF}=\text { Produção total de fitomassa }(\mathrm{g}) \text {. }
$$

$\mathrm{Na}$ mensuração do comprimento e diâmetro da raiz principal do feijão caupi, utilizou-se respectivamente uma régua graduada em centímetro e um paquímetro digital calibrado para medir em milímetros. Os dados coletados foram submetidos a análise da variância pelo Teste $\mathrm{F}$, e quando se verificou efeito significativo nos parâmetros da análise, realizou-se a separação das médias pelo teste de Tukey ( $\mathrm{p} \leq 5 \%$ ), com exceção do fator densidade do solo por conter apenas duas médias. A análise estatística foi realizada com o auxílio do programa computacional para análises estatísticas SAEG v.9.1.

\section{RESULTADOS E DISCUSSÃO}

Os resumos das análises das variâncias para os dados de altura de plantas (ALT), diâmetro do caule (DIAC), número de folhas (NF) e área foliar (AFO) são apresentados na Tabela 1. Houve efeito significativo do fator população de $C$. rotundus L., para todas as características e para o fator compactação do solo pelo teste $\mathrm{F}(\mathrm{p} \leq 0,01)$ para o número de folhas. Também houve efeito, significativo da interação população de tiririca $(\mathrm{T}) \mathrm{x}$ compactação do solo, para as características DIAC, NF e AFO pelo teste F (Tabela 1). 
Tabela 1. Resumos das análises das variâncias para os dados de altura da planta, diâmetro no caule, número de folhas e área foliar do feijão-caupi

\begin{tabular}{lccccc}
\hline \hline \multirow{2}{*}{ Fontes de variação } & \multirow{2}{*}{ GL } & \multicolumn{3}{c}{ Quadrados Médios } \\
& & ALT & DIAC & NF & AFO \\
\hline População de Tiririca (T) & 2 & $92236,12^{* *}$ & $34,0651^{* *}$ & $82,531^{*} *$ & $214231900 * *$ \\
Compactação (C) & 1 & $640,666^{\mathrm{ns}}$ & $0,0077^{\mathrm{ns}}$ & $78,843 * *$ & $5447121^{\mathrm{ns}}$ \\
T x C & 2 & $1378,299^{\mathrm{ns}}$ & $4,179 *$ & $57,593 * *$ & $9142540 *$ \\
Resíduo & 18 & 509,055 & 0,9213 & 5,1562 & 1618137 \\
\hline Total & 23 & - & - & - & - \\
\hline \hline
\end{tabular}

$(* *),(*),($ ns) significativos a $1 \%, 5 \%$ e não significativo respectivamente, pelo teste $\mathrm{F}$.

Para a altura de plantas, constatou-se que, na presença de dois ou mais tubérculos de $C$. rotundus, houve uma redução acentuada em relação ao tratamento sem a presença da Tiririca (Figura 1). Esse resultado é coerente, pois, sob infestação da Cyperaceae, a cultura sofre severa restrição aos recursos de produção, o que resulta em menor crescimento.

As folhas do feijoeiro são emitidas a partir dos nós presentes no caule e, quando a planta tem sua altura reduzida, é possível que haja uma redução no número de folhas e, por conseguinte no aparato fotossintético, também é verdade que as inflorescências são emitidas da axila das folhas, então, se a cultura não tiver um crescimento adequado, ocorrerá à emissão de uma menor quantidade de folhas e de estruturas reprodutivas, comprometendo assim a produção da lavoura.

Figura 1. Altura de planta do feijão-caupi cultivado em ambiente com diferentes populações de $C$. rotundus L.. Letras diferentes nas colunas indicam diferença estatística pelo teste de Tukey a $5 \%$

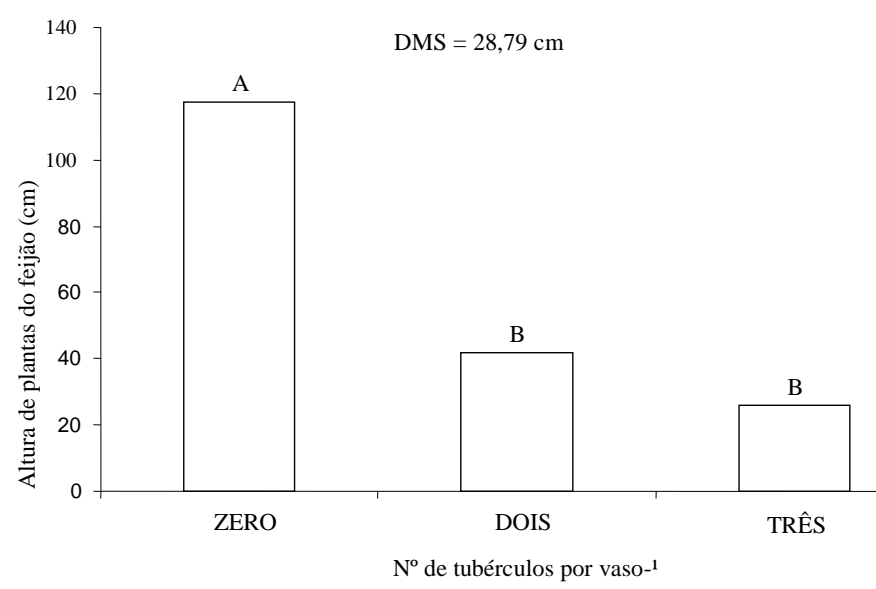

Nas variáveis diâmetro do caule e da raiz, realizou-se o desdobramento da interação significativa em teste de médias, em tal análise, pode-se verificar que nas duas condições de solo, houve influência negativa do semeio de dois ou três tubérculos de C. rotundus, no diâmetro do caule do feijoeiro (Tabela 2).

Quando se estuda o efeito da camada de solo compactada dentro de cada nível populacional de $C$. rotundus, vê-se que houve superioridade das médias obtidas no tratamento sem compactação apenas no nível zero de planta daninha, com isso, infere-se que nos demais níveis a interferência da espécie daninha prevaleceu em relação à compactação do solo, é fato que um bom preparo do solo, capaz de eliminar camadas adensadas, é a condição primordial para um bom estabelecimento de uma lavoura, todavia se esta prática não estiver acompanhada por um bom programa de manejo de plantas daninhas, não terá o efeito esperado.

Tabela 2. Comparação de médias do diâmetro do caule do feijão-caupi cv. BR 17 Gurguéia, em compactado e a infestado com $C$. rotundus $\mathrm{L}$.

\begin{tabular}{|c|c|c|c|c|}
\hline \multirow{3}{*}{ Compactação } & \multicolumn{3}{|c|}{ Número de tubérculos por vaso } & \multirow{3}{*}{ Média } \\
\hline & 0 & 2 & 3 & \\
\hline & \multicolumn{3}{|c|}{-------------------(mm)------------- } & \\
\hline Com & $7,78 \mathrm{Ab}$ & $5,93 \mathrm{Ba}$ & $4,74 \mathrm{Ba}$ & 5,87 \\
\hline Sem & $9,28 \mathrm{Aa}$ & $4,55 \mathrm{Ba}$ & $4,72 \mathrm{Ba}$ & 9,50 \\
\hline Média & $8,53 \mathrm{~A}$ & $5,24 \mathrm{~B}$ & $4,73 \mathrm{~B}$ & 6,16 \\
\hline
\end{tabular}

Médias seguidas de letras iguais maiúsculas nas linhas e minúsculas nas colunas, não diferem estatisticamente entre si pelo teste de Tukey a $5 \%$ de probabilidade.

Pelo desdobramento na interação $\mathrm{T}$ x $\mathrm{C}$, população de tiririca e compactação do solo, pela comparação do teste de média (Tukey $\mathrm{p} \leq 0,05)$ para o componente número de folhas por planta, constatou-se que em solo com camada compactada não houve diferença estatística entre as médias dos tratamentos dentro dos níveis populacionais de $C$. rotundus, esses resultados, diferem dos encontrados por Castellane et al, (2006), ao avaliar o desenvolvimento e produção da soja, observou que quanto maior o nível de compactação menor era a quantidade de folhas por planta. Nos tratamentos sem compactação, o maior número de folhas foi obtido na ausência da Cyperaceae, não havendo diferença estatística quando foram semeados dois ou três tubérculos por vaso (Tabela 3),

Tabela 3. Número de folhas do feijão-caupi cv. BR 17 Gurguéia, sob solo compactado e infestado com C. rotundus L.

\begin{tabular}{|c|c|c|c|c|}
\hline \multirow{3}{*}{ Compactação } & \multicolumn{3}{|c|}{ Número de tubérculos por vaso } & \multirow{3}{*}{ Média } \\
\hline & 0 & 2 & 3 & \\
\hline & \multicolumn{3}{|c|}{--------------- unidade ------------------ } & \\
\hline Com & $6,50 \mathrm{Ab}$ & $5,50 \mathrm{Aa}$ & $5,62 \mathrm{Aa}$ & $5,87 \mathrm{~b}$ \\
\hline Sem & $16,25 \mathrm{Aa}$ & $6,88 \mathrm{Ba}$ & $5,38 \mathrm{Ba}$ & $9,50 \mathrm{a}$ \\
\hline Média & $11,37 \mathrm{~A}$ & $6,12 \mathrm{~B}$ & $5,50 \mathrm{~B}$ & 7,68 \\
\hline
\end{tabular}

Médias seguidas de letras iguais maiúsculas nas linhas e minúsculas nas colunas, não diferem estatisticamente entre si pelo teste de Tukey a 5\% de probabilidade.

Com tais resultados pode-se conjecturar que o número de folhas do feijão-caupi sofre forte redução na presença da barreira física no solo, a qual impede o crescimento normal do sistema radicular e a captação de recurso do meio de cultivo, e tal redução pode se tornar mais acentuada na presença de plantas daninhas, mesmo em solo sem camada de impedimento. 
Nesse sentido Silva e Silva (2007) alertam que o preparo inadequado do solo estabelece uma condição que desfavorece a cultura, normalmente menos adaptada a tais condições, ao passo que favorece espécies vegetais mais rústicas, como as plantas daninhas, o que pode ser verificado pela maior densidade de plantas daninhas no rastro da roda do trator dias após o preparo do solo.

Estudando-se o fator compactação do solo dentro dos níveis de plantas daninhas (Tabela 3), observou-se diferença significativa com a utilização da quantidade zero de $C$. rotundus, onde o maior número de folhas foi obtido no tratamento sem camada compactada, o que reforça a hipótese de que o preparo adequado do solo é de suma importância para o perfeito crescimento do feijão-caupi, salientando-se que a emissão de um número adequado de folhas, maior aparato fotossintético, representa maior índice de área foliar, o que pode resultar em um melhor enchimento de drenos, conforme salienta Mendes et al. (2007).

Ao se analisar os dados da área foliar do feijoeiro cultivado em ambiente com diferentes populações de $C$. rotundus em solo compactado, verificou-se maior interferência da planta daninhas nos tratamento onde foram semeados três tubérculos. Em tais condições, é possível que a compactação do solo tenha potencializado e intensificado a interferência da planta daninha, fazendo com que o feijãocaupi, produzisse uma menor área foliar (Tabela 4). Tal comportamento pode ser explicado pelo fato de a compactação do solo ser uma condição que interfere na utilização dos recursos pelas plantas cultivadas, especialmente sob infestação de espécies daninhas altamente competitivas e com vigoroso sistema radicular, como é o caso de $C$. rotundus.

No solo sem compactação a redução significativa da área foliar do feijão-caupi ocorreu quando foram semeados dois e três tubérculos por vaso, por outro lado sem a presença de $C$. rotundus, e sem a compactação da camada subsuperficial do solo o feijoeiro apresentou notável área foliar (Tabela 4).

$\mathrm{O}$ aumento da área foliar proporciona uma maior superfície fotossintética, assegurando aproveitamento mais eficiente das baixas intensidades luminosas e, consequentemente, compensando as baixas taxas de fotossíntese por unidade da área foliar, característica da folha sombreada. Além disso, o aumento dessa variável pelas plantas da cultura resulta em maior sombreamento da comunidade infestante, com consequente redução de sua capacidade competitiva, notadamente, se as plantas daninhas sombreadas apresentarem rota fotossintética $\mathrm{C}_{4}$.

Tabela 4. Área foliar do feijoeiro cultivado em ambiente com diferentes populações de $C$. rotundus L. e condições de solo

\begin{tabular}{ccccc}
\hline \hline \multirow{2}{*}{ Compactação } & \multicolumn{4}{c}{ Número de tubérculos por vaso } \\
\cline { 2 - 5 } & \multicolumn{4}{c}{ Média } \\
\cline { 2 - 5 } & $2.314,43 \mathrm{Ab}$ & 2 & 3 \\
\hline Com & $5.571,47 \mathrm{Aa}$ & $1.687,66 \mathrm{Aa}$ & $737,61 \mathrm{Ba}$ \\
\hline Média & $3.942,95 \mathrm{~A}$ & $7.20,78 \mathrm{Ba}$ & $1.305,88 \mathrm{Ba}$ & $2.532,71$ \\
\hline \hline
\end{tabular}

Médias seguidas de letras iguais maiúsculas nas linhas e minúsculas nas colunas, não diferem estatisticamente entre si pelo teste de Tukey a $5 \%$ de probabilidade.

Estudando-se o efeito da compactação do solo dentro de cada nível populacional de $C$. rotundus, verificou-se maior área foliar nas plantas cultivadas em solo não compactado e sem a presença da planta daninha, nos demais tratamentos não houve efeito depreciativo significativo da compactação do solo sob a área foliar do feijoeiro (Tabela 4), resultados semelhantes aos encontrados por Silva et al, (2006), que verificou um menor índice de área foliar, em solos compactados. Com isto, supõe-se que a compactação do solo isoladamente pode afetar a expansão da área foliar do caupi, mas quando existe outro fator passível de interferir em tal característica a compactação do solo passa a ser algo secundário em relação a maior interferência provocada pelas plantas daninhas que reduziu igualmente a área foliar da cultura nas duas condições de solo não havendo, portando, efeito significativo da compactação do solo quando o ambiente estava infestado com $C$. rotundus.

Pelos quadrados médios de tratamentos, verificou-se efeito significativo da presença da Tiririca (Cyperus rotundus L.) no que diz respeito à Fitomassa Fresca da Parte Aérea (FFPA), Fitomassa Fresca das Raízes (FFRA) e Fitomassa Fresca Total (FFT) e Relação Raiz Parte Aérea (RRPA) do feijoeiro. Em relação à compactação do solo, a única característica que sofreu influência foi a Fitomassa Fresca das Raízes, aspecto também visualizado na interação População Tiririca x Compactação (Tabela 5).

Tabela 5. Resumo da análise de variância para os dados de produção de Fitomassa Fresca da Parte Aérea (FFPA) (g), Fitomassa Fresca de Raízes (FFRA) (g) e Fitomassa Fresca Total (FFT) (g) do feijoeiro

\begin{tabular}{lccccc}
\hline \hline \multirow{2}{*}{ Fontes de variação } & \multirow{2}{*}{ GL } & \multicolumn{4}{c}{ Quadrados Médios } \\
& & FFPA & FFRA & FFT & RRPA \\
\hline População de Tiririca (T) & 2 & $54227 * *$ & $4710 * *$ & $90444 * *$ & $0,2698 * *$ \\
Compactação (C) & 1 & $0,4421 \mathrm{~ns}$ & $1153 *$ & $1109 \mathrm{~ns}$ & $0,00076 \mathrm{~ns}$ \\
T x C & 2 & $5330 \mathrm{~ns}$ & $1892 *$ & $13023 \mathrm{~ns}$ & $0,3734 \mathrm{~ns}$ \\
\hline Resíduo & 18 & 4633 & 315,58 & 5798 & 0,2143 \\
Total & 23 & - & - & - & - \\
\hline \hline
\end{tabular}

$(* *),(*),($ ns) significativos a $1 \%, 5 \%$ e não significativo respectivamente, pelo teste $\mathrm{F}$. 
Estudando-se os dados de fitomassa fresca da parte aérea, por meio do teste de média, verificou-se uma menor produção de fitomassa na medida em que se aumentou a quantidade de tubérculos de $C$. rotundus semeados por vaso, o que indica menor crescimento da cultura do feijão-caupi em condição de alta infestação de plantas daninhas, bem como a necessidade de um adequado manejo das estruturas de reprodução presentes no solo. Na ausência dos tubérculos obteve-se valor de produção de fitomassa de $750 \%$ superior ao valor observado quando o feijão foi semeado em vaso com três tubérculos (Figura 2). Corroborando com informações de Muniz (2007) ao constatar que a presença de C. rotundus, mesmo em baixa infestação, causou interferência no crescimento e desenvolvimento do feijoeiro, provavelmente devido ao fato de se propagar rapidamente por tubérculos e também por exsudar aleloquímicos. No presente estudo, houve efeito significativo sobre a produção de fitomassa da parte aérea quando foram semeados dois e três tubérculos por vaso (Figura 2).

Figura 2. Produção de fitomassa fresca da parte aérea do feijão-caupi (FFPA), sob infestação por C. rotundus L. As letras diferentes nas colunas indicam diferença estatística entre as médias de tratamentos pelo teste de Tukey $(\mathrm{p} \leq 0,05)$

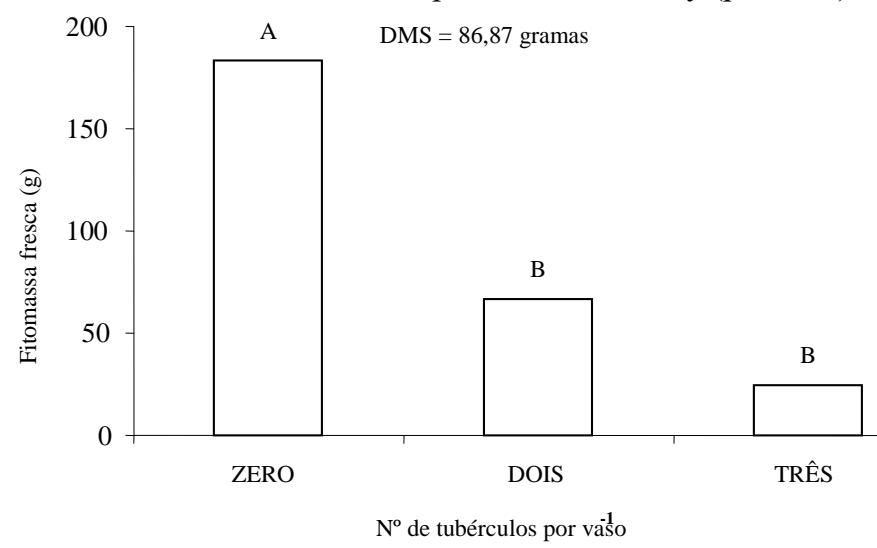

No desdobramento da interação $\mathrm{T}$ x $\mathrm{C}$, para a característica fitomassa fresca das raízes, verificou-se que a compactação do solo afetou o crescimento das raízes na ausência de $C$. rotundus, nos demais tratamentos não houve efeito significativo da compactação, é possível que a alta infestação de $C$. rotundus, tenha limitado o crescimento das raízes do feijoeiro na camada superficial do solo, fazendo com que a compactação tivesse seu efeito mascarado pela maior agressividade da planta daninha, já no tratamento sem C. rotundus, as raízes do feijoeiro, acumularam uma maior quantidade de fitomassa fresca em solo sem compactação, onde o valor foi estatisticamente superior ao verificado no solo compactado (Tabela 6).

Tabela 6. Produção de fitomassa fresca de raízes (FFRA) do feijoeiro

\begin{tabular}{|c|c|c|c|c|}
\hline \multirow{2}{*}{ Compactação } & \multicolumn{3}{|c|}{ Número de tubérculos por vaso } & \multirow{2}{*}{ Média } \\
\hline & 0 & 2 & 3 & \\
\hline Com & $20,63 \mathrm{Ab}$ & $9,46 \mathrm{Aa}$ & $0,93 \mathrm{Ba}$ & $10,34 \mathrm{~b}$ \\
\hline Sem & $69,71 \mathrm{Aa}$ & $1,70 \mathrm{Ba}$ & $1,21 \mathrm{Ba}$ & $24,20 \mathrm{a}$ \\
\hline Média & $45,17 \mathrm{~A}$ & $5,58 \mathrm{~B}$ & 1,07 B & 17,27 \\
\hline
\end{tabular}

Médias seguidas de letras iguais maiúsculas nas linhas e minúsculas nas colunas, não diferem estatisticamente entre si pelo teste de Tukey a 5\% de probabilidade.
Do mesmo modo que para os dados de FFPA e FFRA, à produção de fitomassa fresca total (FFT) também sofreu interferência negativa das plantas daninhas e, quanto maior o número de tubérculos no vaso, menor foi à produção de fitomassa fresca do feijoeiro (Figura 3).

Figura 3. Produção de fitomassa fresca total do feijoeiro cultivado em ambiente com diferentes populações de tiririca. Letras diferentes nas colunas indicam diferença estatística pelo teste de Tukey a $5 \%$

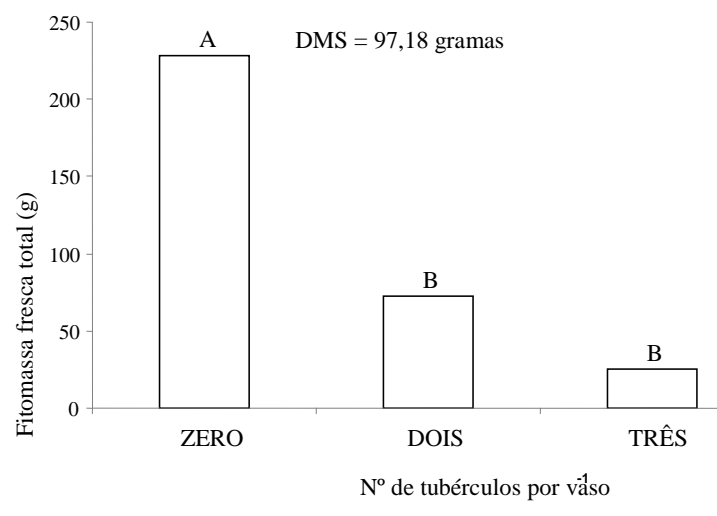

Para a relação/raiz parte aérea do feijoeiro cultivado em ambiente com diferentes populações de $C$. rotundus, verificou-se que a presença de dois ou mais tubérculos ocasiona efeito depreciativo na variável (Figura 4). No tratamento sem $C$. rotundus, a produção de fitomassa radicular foi equivalente a $70 \%$ da fitomassa da parte aérea e à medida que se aumentou a densidade de $C$. rotundus no substrato, houve redução na produção de fitomassa radicular em relação à aérea, infere-se, portanto, que a interferência da planta daninha sobre o caupi, atinge tanto a fitosfera quanto a rizosfera, havendo menor produção de raízes em ambiente sob forte infestação de C. rotundus, especialmente quando existe limitação no ambiente radicular, o que leva a maior disputa pelo recurso do meio e, em tais condições, é comum que a espécie mais agressiva se sobressaia, frente à outra menos competitiva.

Figura 4. Relação raiz parte aérea do feijoeiro cultivado em ambiente com diferentes populações de C. rotundus L.. Letras diferentes nas colunas indicam diferença estatística pelo teste de Tukey a $5 \%$

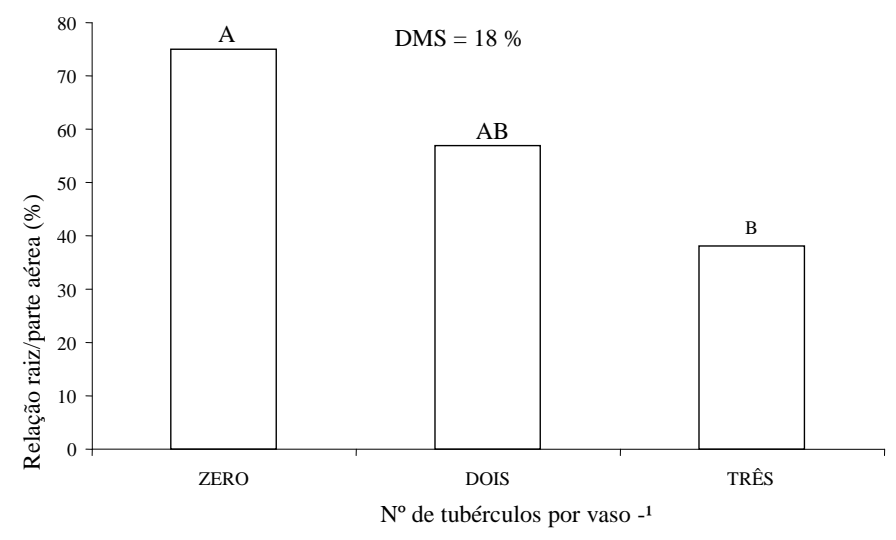

No tocante a produção de fitomassa seca da parte aérea (FSPA), fitomassa seca das raízes (FSRA) e fitomassa seca 
total (FST) do feijoeiro, constatou-se diferença estatística apenas no fator população de tiririca $(\mathrm{F} \leq 0,01)$, enquanto no fator compactação, bem como para a interação $\mathrm{T}$ x $\mathrm{C}$, os dados não diferiram estatisticamente pelo teste $\mathrm{F}$ (Tabela 7).

Tabela 7. Resumos das análises das variâncias para os dados de produção de fitomassa seca da parte aérea (FSPA), fitomassa seca de raízes (FSRA) e fitomassa seca total (FST) do feijão-caupi

\begin{tabular}{lcccc}
\hline \hline \multirow{2}{*}{ Fontes de variação } & GL & & Quadrados Médios & FST \\
& & FSPA & FSRA & $886,5843 * *$ \\
Tiririca (T) & 2 & $615,5824 * *$ & $25,0268 * *$ & $4,8613 \mathrm{~ns}$ \\
Compactação (C) & 1 & $4,9472 \mathrm{~ns}$ & $0,00037 \mathrm{~ns}$ & $167,3387 \mathrm{~ns}$ \\
T x C & 2 & $123,5753 \mathrm{~ns}$ & $3,3928 \mathrm{~ns}$ & 93,3630 \\
\hline Resíduo & 18 & 66,2053 & 2,6322 & - \\
\hline Total & 23 & - & - & - \\
\hline \hline
\end{tabular}

$\left({ }^{* *}\right),(*),(\mathrm{ns})$ significativos a $1 \%, 5 \%$ e não significativo respectivamente, pelo teste $\mathrm{F}$.

Analisando-se os dados da produção de fitomassa seca da parte aérea (FSPA) (g), fitomassa seca das raízes (FSRA) (g) e fitomassa seca total (FST) (g) do feijoeiro em relação a ambientes com diferentes populações de $C$. rotundus, constatou-se que quando se semearam dois ou três tubérculos por vaso, a FSPA e FST, sofreram decréscimos significativos (Figura 5 A, B e C).

Figura 5. Produção de fitomassa seca da parte aérea (A) da raiz (B) e total (C) do feijão-caupi, cultivado em ambiente com diferentes populações de $C$. rotundus L. Letras diferentes nas colunas indicam diferença estatística pelo teste de Tukey a 5\%
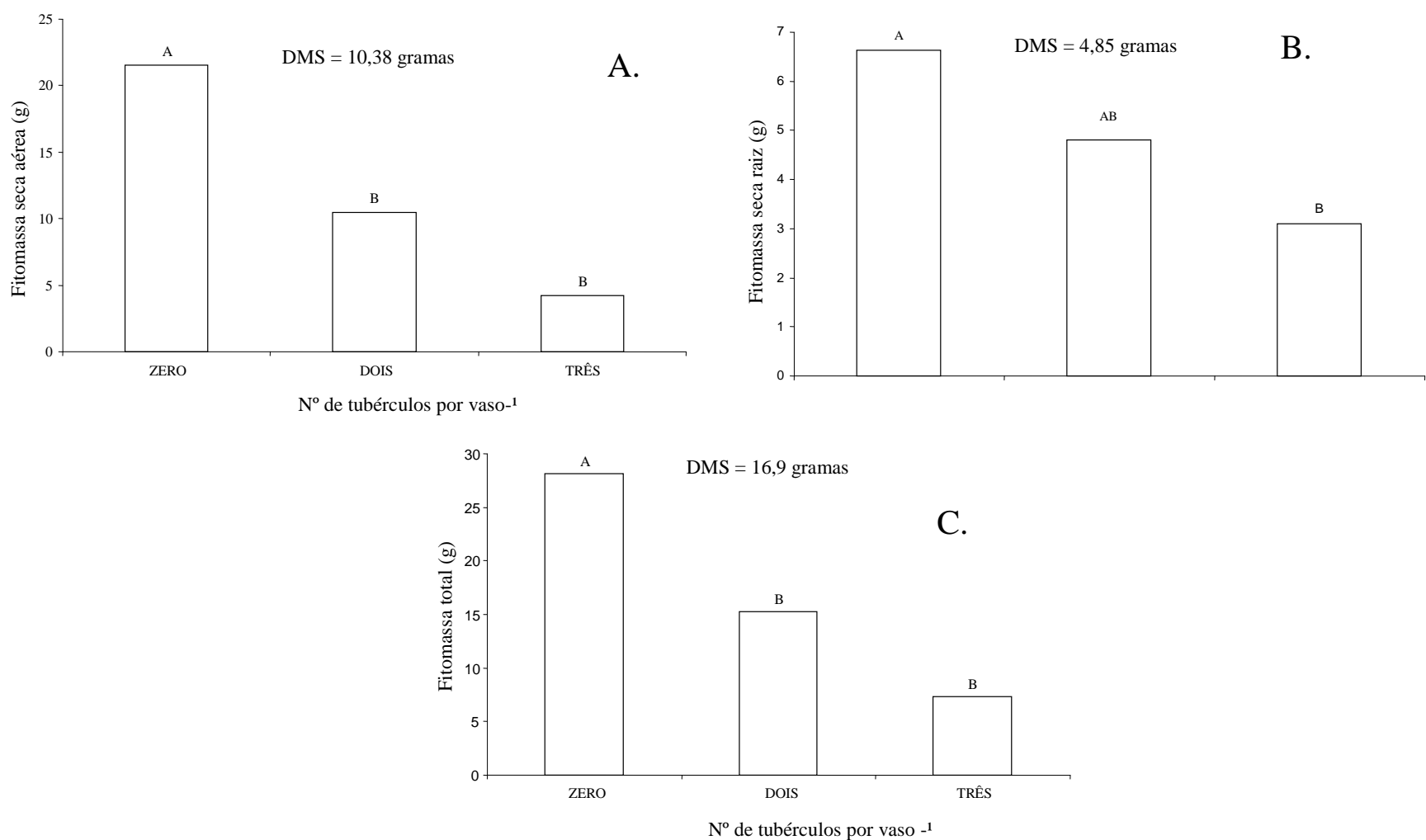

Tais resultados são condizentes com informações de Silva e Silva (2007), ao relatarem que o grau de interferência das plantas daninhas sobre as culturas depende, dentre outros fatores, da densidade e da espécie de plana daninha presente no agroecossistema.

Com relação à distribuição relativa de fitomassa seca do feijão-caupi, constatou-se que houve maior produção nas folhas em todos os tratamentos com valores que variaram de 50 a $70 \%$ do total de fitomassa produzido, no tratamento com três tubérculos de tiririca e sem compactação do solo (T3SO) e sem tubérculos e livre de compactação (TOS0), respectivamente (Figura 6).

O maior acúmulo de fitomassa foliar no tratamento TOS0, onde não havia interferência de C. rotundus, nem compactação do solo, deve-se ao estabelecimento de maior aparato fotossintético com reflexos positivos na produtividade da lavoura. Vale salientar que foi também em tal tratamento onde se obteve a maior produção de fitomassa em termos absolutos, portanto, o correto manejo do solo aliado ao controle de plantas daninhas são práticas culturais primordiais para o bom crescimento do feijão-caupi. Depois das folhas 
houve um maior acúmulo de fitomassa nas raízes seguidas do caule que acumulou a menor quantidade em todos os tratamentos (Figura 6).

Figura 6. Produção e distribuição relativa de fitomassa seca do feijoeiro cultivado em ambiente com diferentes populações de tiririca. TOS1 (cultivo livre de infestação e solo compactado); T2S1 (solo compactado na subsuperfície e semeio de dois tubérculos de tiririca); T3S1 (Solo compactado na subsuperfície e semeio de três tubérculos de tiririca); TOSO (Solo sem compactação e sem a presença de tiririca); T2S0 (Solo sem compactação e semeio de dois tubérculos de tiririca); T3S0 (Solo sem compactação e semeio de três tubérculos de tiririca)

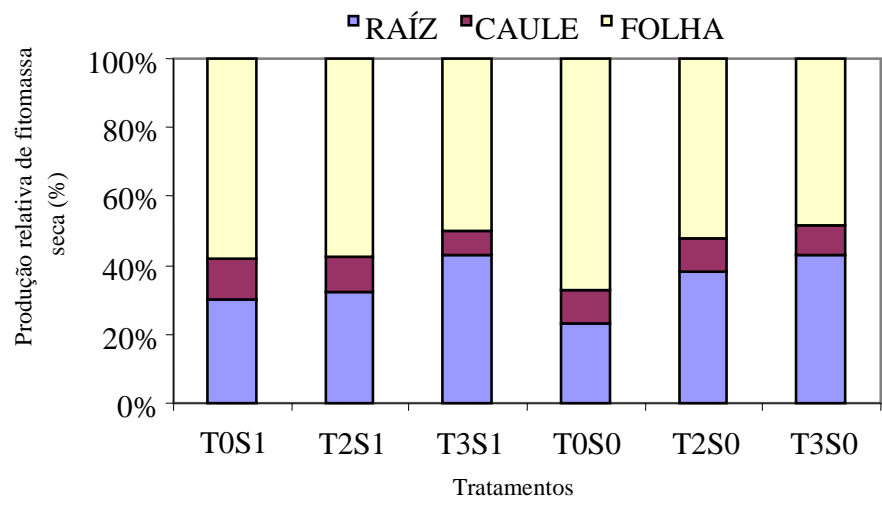

Pelos resumos das análises das variâncias para os dados de diâmetro da raiz (DIAR) e comprimento da raiz (COMPR) do feijão-caupi, constatou-se efeito significativo na interação níveis de $C$. rotundus $\mathrm{x}$ Compactação do solo para a característica diâmetro da raiz, conforme teste $\mathrm{F}$ a $5 \%$ de probabilidade, por outro lado não houve efeito significativo dos tratamentos sobre o comprimento da raiz (Tabela 8).

Tabela 8. Resumos das análises das variâncias para os dados de diâmetro da raiz (DIAR) e comprimento da raiz (COMPR) do feijão-caupi

\begin{tabular}{lccc}
\hline \hline \multirow{2}{*}{ Fontes de variação } & \multirow{2}{*}{ GL } & \multicolumn{2}{c}{ Quadrados Médios } \\
& & DIAR & COMPR \\
\hline População de Tiririca (T) & 2 & $45,59 * *$ & $9,041 \mathrm{~ns}$ \\
Compactação (C) & 1 & $0,0748 \mathrm{~ns}$ & $2,041 \mathrm{~ns}$ \\
T x C & 2 & $4,721 *$ & $3,166 \mathrm{~ns}$ \\
\hline Resíduo & 18 & 1,2124 & 4,0763 \\
Total & 23 & - & - \\
\hline \hline
\end{tabular}

$(* *),(*),(n s)$ significativos a $1 \%, 5 \%$ e não significativo respectivamente, pelo teste $\mathrm{F}$.

Estudando-se o efeito da interferência de C. rotundus, dentro de cada condição de solo, verificou-se que o diâmetro da raiz sofreu redução na presença da planta daninha nas duas condições de solo, quando foram semeados dois ou três tubérculos por vaso, e a compactação do solo só reduziu o diâmetro radicular nos vasos sem a presença da Cyperaceae (Tabela 9), indicando, mais uma vez, que os maiores danos ao crescimento do caupi estão mais associados à planta daninha do que a condição do solo isoladamente, já que em tais condições a espécie daninha quase sempre se sobressai frente à cultura.
Tabela 9. Diâmetro da raiz do feijão-caupi cv. BR 17 Gurguéia, sob solo compactado e infestado com C. rotundus L.

\begin{tabular}{|c|c|c|c|c|}
\hline \multirow{3}{*}{ Compactação } & \multicolumn{3}{|c|}{ Número de tubérculos por vaso } & \multirow{3}{*}{ Média } \\
\hline & 0 & 2 & 3 & \\
\hline & \multicolumn{3}{|c|}{---------------------(mm)-------------- } & \\
\hline Com & $7,36 \mathrm{Ab}$ & $5,36 \mathrm{Ba}$ & $3,86 \mathrm{Ba}$ & 5,52 \\
\hline Sem & $8,95 \mathrm{Aa}$ & $3,96 \mathrm{Ba}$ & $3,34 \mathrm{Ba}$ & 5,41 \\
\hline Média & $8,16 \mathrm{~A}$ & $4,65 \mathrm{~B}$ & $3,59 \mathrm{~B}$ & 5,47 \\
\hline
\end{tabular}

Médias seguidas de letras iguais maiúsculas nas linhas e minúsculas nas colunas, não diferem estatisticamente entre si pelo teste de Tukey a 5\% de probabilidade.

\section{CONCLUSÕES}

O crescimento do feijão-caupi representado pelos componentes, altura de plantas, número de folhas diâmetro do caule, área foliar e produção de fitomassa seca é fortemente afetado pela presença de $C$. rotundus, no meio de cultivo, a qual deve ser controlada para reduzir sua interferência sobre a cultura.

A presença da camada compactada de solo prejudica os componentes de crescimento do feijão-caupi, sendo potencializado, pela presença da planta daninha.;

\section{REFERÊNCIAS BIBLIOGRÁFICAS}

CUDNEY, D. Nutsedge: history, economy, importance and distribution. In: NUTSEDGE Management Workshop. Riverside: University of Califórnia, 1997.

CASTEllanE, P. D. et al. Compactação do solo no desenvolvimento e na produção de cultivares de soja. Científica, Jaboticabal, v.34, n.2, p. , 2006 203-209 203.

FREIRE FILHO, F. R.; SANTOS, A. A. dos; CARDOSO, M. J.; SILVA, P. H. S. da; RIBEIRO, V. Q. BR 17 GURGUÉIA: nova cultivar de caupi com resistência a vírus para o Piauí. Teresina: EMBRAPA-CPAMN, 2008. 2 p.

FREITAS, F.C.L. et al. Interferência de plantas daninhas na cultura do feijão-caupi. Planta daninha [online]. 2009, vol.27, n.2, pp. 241-247. ISSN 1806-9681.

GUIMARÃES, C. M.; STONE, L. F.; MOREIRA, J. A. A. Compactação do solo na cultura do feijoeiro. II: efeito sobre o desenvolvimento radicular e da parte aérea. Rev. bras. eng. agríc. ambient., Campina Grande, v. 6, n. 2002 .

MORAES, P. V. D. et al. Competitividade relativa de soja com arroz-vermelho. Planta Daninha, v. 27, n. 1, p. 3540, 2009.

MUNIZ, F. R. et al. Qualidade fisiológica de sementes de milho, feijão, soja e alface na presença de extrato de tiririca. Revista Brasileira de Sementes, v.29, p.195-204, 2007.

MENDES, R. M. de S.; TÁVORA, F. J. A. F.; PITOMBEIRA, J. B. NOGUEIRA, R. J. M. C. Relações fonte-dreno em feijão-decorda submetida à deficiência 
hídrica. Revista Ciência Agronomia, v.38, n.1, p.95-103, 2007.

OLIVEIRA, O. M. S. et al . Período de convivência das plantas daninhas com cultivares de feijão-caupi em várzea no Amazonas. Planta daninha, Viçosa, v. 28, n.3, 2010 Disponível em: <http://www.scielo.br/scielo.php?script=sci_arttext\&pid =S010083582010000300009\&lng=en\&nrm=iso >.

Acesso em: 16 Set. 2011.

PASTRE, W. Controle de tiririca (Cyperus rotundus L.) com aplicação de sulfentrazone e flazasulfuron aplicados isoladamente e em mistura na cultura da cana-de-açúcar. Dissertação (Mestrado em Tecnologia da Produção Agrícola) - Pós-Graduação - IAC. 2006. $53 f$

SINGH, B. B.; EHLERS, J. D.; SHARMA, B.; FREIRE FILHO, F. R. Recent progress in cowpea breeding. In: FATOKUN, C. A.; TARAWALI, S. A.; SINGH, B. B.; KORMAWA, P. M.; TAMÒ, M. *Challenges and oportunities for enhancing sustainable cowpea production*. Ibadan: IITA, 2002. 433p.

SILVA, A. A. da; SILVA, J. F. da (Eds.). Tópicos em manejo de plantas daninhas. Viçosa: UFV, 2007, 367 p.: il.

SILVA, G. J. et al. Crescimento da parte aéria de plantas cultivadas em vaso, submetidas à irigação subsuperficial e a diferentes graus de compactação de um latossolo vermelho-escuro distrófico. R. Bras. Ci. Solo, 30:31-40, 2006. 